\title{
Contemporary incidence and mortality rates of kidney cancer in the United States
}

\author{
Giorgio Gandaglia, MD; ${ }^{*}$ Praful Ravi, MD; ; Firas Abdollah, MD; ${ }^{*}$ Abd-El-Rahman M. Abd-El-Barr, MD;, \\ Andreas Becker, MD;: Ioana Popa, MD; Alberto Briganti, MD;* Pierre I. Karakiewicz, MD, FRCSC ${ }^{\S}$

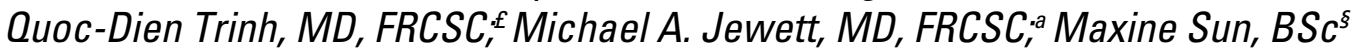

\begin{abstract}
*Department of Urology, Vita Salute San Raffaele University, Milan, Italy; 'West Middlesex University Hospital, London, United Kingdom; *Vattikuti Urology Institute, Henry Ford Health Systems, Detroit, Ml; §Cancer Prognostics and Health Outcomes Unit, University of Montreal Health Center, Montreal, QC; \pm Department of Urology, Prostate Cancer Center, University of Hamburg-Eppendorf, Hamburg, Germany; ${ }^{E}$ Department of Surgery, Division of Urology, Brigham and Women's Hospital/Dana-Farber Cancer Institute, Harvard Medical School, Boston, MA; Department of Surgical Oncology, Division of Urology, University Health Network, Toronto, ON
\end{abstract}

Cite as: Can Urol Assoc J 2014;8(7-8):247-52. http://dx.doi.org/10.5489/cuaj.1760 Published online August 11, 2014.

\section{Abstract}

Introduction: This is a timely update of incidence and mortality for renal cell carcinoma (RCC) in the United States.

Methods: Relying on the Surveillance, Epidemiology, and End Results (SEER) database, we computed age-adjusted incidence, mortality rates and 5-year cancer-specific survival (CSS) for patients with histologically confirmed kidney cancer between 1975 and 2009. Long-term (1975-2009) and short-term (2000-2009) trends were examined by joinpoint analysis, and quantified using the annual percent change (APC). The reported findings were stratified according to disease stage.

Results: Age-adjusted incidence rates of RCC increased by $+2.76 \%$ / year between 1975 and 2009 (from 6.5 to 17.1/100 000 personyears, $p<0.001)$, and by $+2.85 \% /$ year between 2000 and 2009 $(p<0.001)$. For the same time points, the corresponding APC for the incidence of localized stage were $+4.55 \% / y e a r$ (from 3.0 to $12.2 / 100000$ person years, $p<0.001$ ), and $+4.42 \% /$ year $(p<0.001)$, respectively. The incidence rates of regional stage increased by $+0.88 \%$ /year between 1975 and $2009(p<0.001)$, but stabilized in recent years (2000-2009: $+0.56 \% /$ year, $p=0.4$ ). Incidence rates of distant stage remained unchanged in long- and short-term trends. Overall mortality rates increased by $+1.72 \% /$ year between 1975 and 2009 (from 1.2 to 5.0/100 000 person-years, $\mathrm{P}<0.001)$, but stabilized between 1994 and $2004(p=0.1)$. Shortterm mortality rates increased in a significant fashion by $+3.14 \%$ / year only for localized stage $(p<0.001)$.

Interpretation: In contemporary years, there is a persisting upward trend in incidence and mortality of localized RCC.

\section{Introduction}

An estimated 64770 new cases of kidney cancer were diagnosed in 2012 in the United States, with about 13570 new deaths due to the disease. ${ }^{1}$ Previous studies reported that the incidence of kidney cancer showed no signs of stabilizing over the past 3 decades, ${ }^{2-4}$ coinciding with an increased use of imaging, namely abdominal ultrasound and computed tomography (CT). ${ }^{5}$ This postulation is somewhat substantiated given that previous reports showed that the increase in incidence was predominantly driven by localized stage. ${ }^{2}$

However, such trends may have changed in recent years for two reasons. First, decreasing incidence rates for several cancers have been reported. ${ }^{6}$ Second, a recent study showed a plateau, and even reduction, in the use of imaging studies between 2006 and 2010. ${ }^{7}$ Under this setting, we sought to examine how these changes may have affected incidence and mortality rates of kidney cancer over time. We hypothesized that incidence rates of kidney cancer should also have decreased, or at the minimum stabilized, in recent years.

\section{Methods}

\section{Study source}

Population-based data on cancer incidence were abstracted from the National Cancer Institute (NCI)'s Surveillance, Epidemiology, and End Results (SEER) program. The identification of individuals with kidney cancer diagnosed between 1975 and 2009 were based on 13 cancer registries in the SEER Program and account for about $14 \%$ of the US population. ${ }^{8}$

\section{Study population}

Patients with histologically confirmed cases of cancers of the kidney parenchyma, or kidney not otherwise specified (International Classification of Diseases Oncology [ICDO-2], site code C64.9) were abstracted using previously described methodologies. ${ }^{2,3}$ For the purpose of the analyses, we excluded in situ and unstaged disease. Moreover, analyses were restricted to patients aged $\geq 18$ years old. 
Gandaglia et al.

\begin{tabular}{l}
$\begin{array}{l}\text { Table 1. Description of the staging system defined by } \\
\text { the Surveillance, Epidemiology, and End Results (SEER) } \\
\text { database }\end{array}$ \\
\begin{tabular}{ll} 
SEER stage & \multicolumn{1}{c}{ Description } \\
\hline Localized & $\begin{array}{l}\text { An invasive malignant cancer confined entirely } \\
\text { to the organ of origin. }\end{array}$ \\
\hline & $\begin{array}{l}\text { A malignant cancer that (1) has extended } \\
\text { beyond the limits of the organ of origin directly } \\
\text { into surrounding organs or tissues; (2) involves } \\
\text { regional lymph nodes by way of lymphatic } \\
\text { system; or (3) has both regional extension } \\
\text { and involvement of regional to distant organs, } \\
\text { tissues, or via the lymphatic system to distant } \\
\text { lymph nodes. }\end{array}$ \\
\hline Distant & $\begin{array}{l}\text { A malignant cancer that has spread to parts } \\
\text { of the body remote from the primary tumour } \\
\text { either by direct extension or by discontinuous } \\
\text { metastasis to distant organs, tissues, or via the } \\
\text { lymphatic system to distant lymph nodes. }\end{array}$ \\
\hline SEER: Surveillance, Epidemiology, and End Results.
\end{tabular} \\
\hline
\end{tabular}

\section{Statistical analyses}

For the purpose of our analyses, cases were grouped according to SEER staging systems, defined as localized, regional and distant (Table 1). Overall incidence, mortality, and the 5-year cancer-specific survival (CSS) were computed within the entire cohort, and stratified according to disease stage. Incidence rates and incidence-based mortality rates were adjusted to the 2000 United States standard population, and calculated per 100000 person-years. Temporal trends of age-adjusted rates were assessed using joinpoint regression, which involves fitting a series of joined straight lines on a logarithmic scale to the trends in the annual ageadjusted rates, ${ }^{9}$ and quantified using the annual percent change (APC). Both long-term (1975-2009) and short-term (2000-2009) trends were examined. The time frame interval for short-term trends assessment in mortality rates were limited to diagnoses between 1994 and 2004, to allow at least 5 years of follow-up. The $t$ test was used to assess whether the APCs were statistically significantly different. All statistical tests were two-sided, with a significance level set at 0.05 .

\section{Results}

\section{Incidence}

Overall age-adjusted incidence of kidney cancer steadily increased by $+2.76 \%$ /year $(95 \%$ confidence interval $[\mathrm{Cl}]$
A

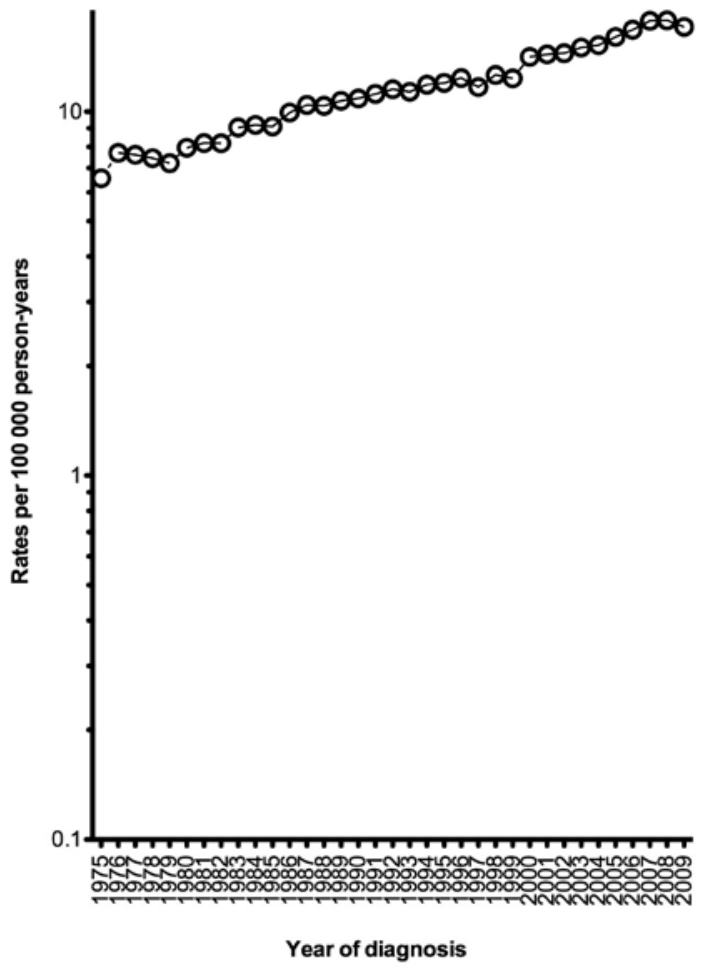

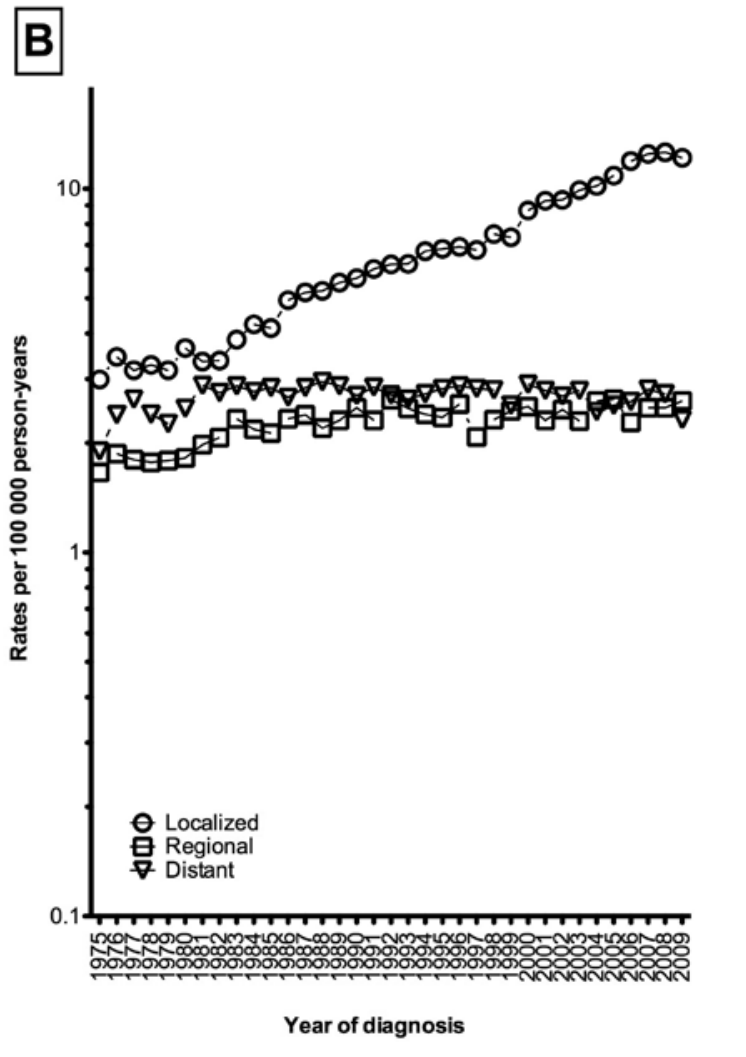

Fig. 1. Overall age-adjusted incidence rates of kidney cancer $[A]$ and stratified according to disease stage [B], Surveillance, Epidemiology, and End Results (SEER), 1975-2009. 


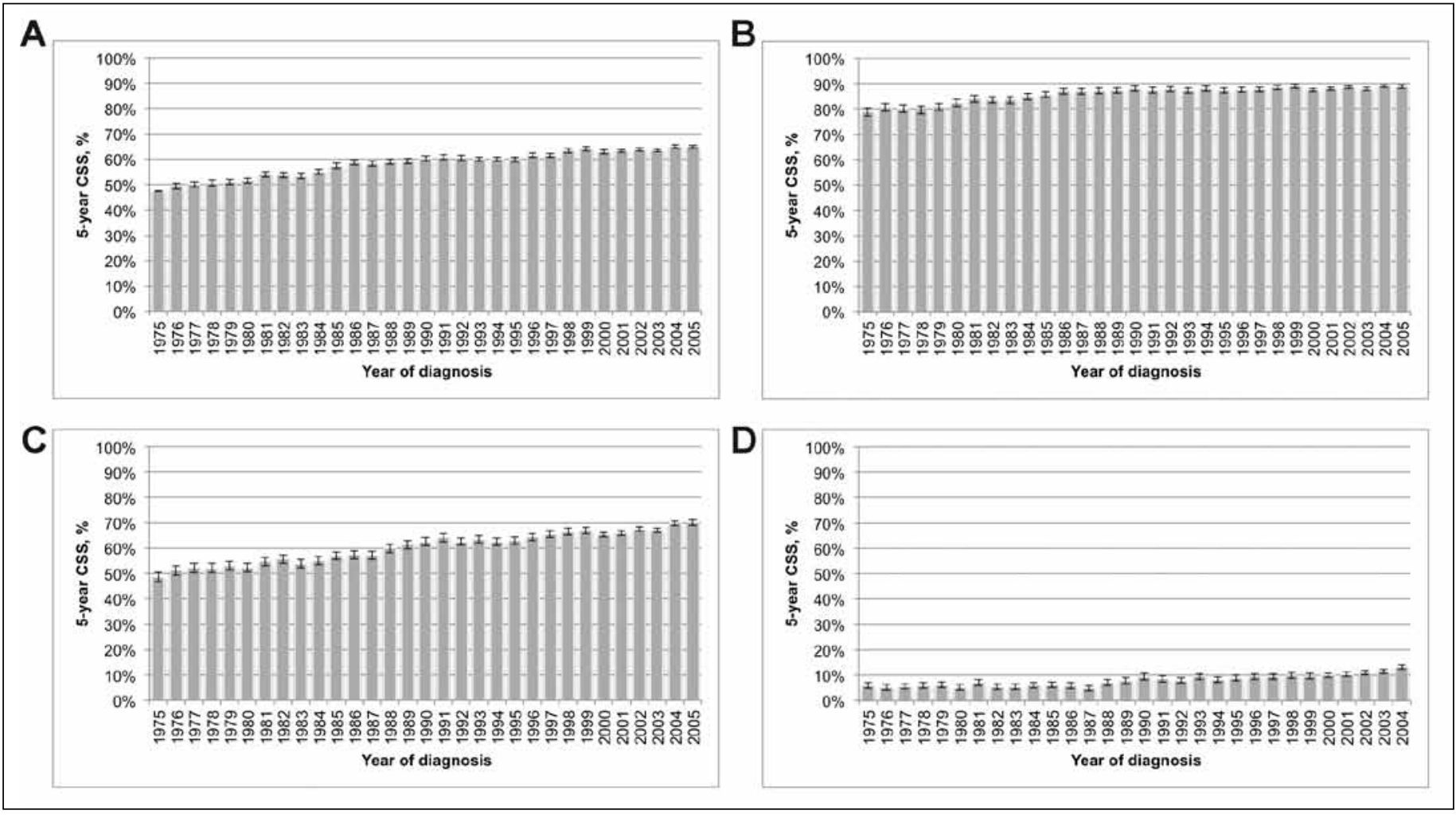

Fig. 2. Five-year cancer-specific survival among all patients diagnosed with kidney cancer $[A]$, patients with localized disease $[B]$, with regional disease $[C]$, and with distant disease [D], Surveillance, Epidemiology, and End Results (SEER), 1975-2005.

2.61-2.91, $p<0.001$ ) between 1975 and 2009 (from 6.56 to 17.09 per 100000 person-years, Fig. 1, part A). Short-term trends revealed similar significant increases, where between 2000 and 2009 the incidence rose significantly by $+2.85 \% /$ year $(95 \% \mathrm{Cl} 2.06-3.64 \%, p<0.001$, Table 2$)$. In stage-specific analyses, the results showed that age-adjusted incidence rates of localized kidney cancer increased by $+4.55 \%$ (95\% $\mathrm{Cl} 4.34-4.76 \%, p<0.001$ ) between 1975 and 2009 (from 2.99 to 12.16 per 100000 person-years, Fig. 1, part B), and by $+4.42 \%(95 \% \mathrm{Cl} 3.40-5.46 \%, p<0.001)$ between 2000 and 2009. The incidence rates of regional disease increased by $+0.88 \%(95 \% \mathrm{Cl} 0.60-1.15 \%, p<0.001)$ from 1975 to 2009 (from 1.66 to 2.61 per 100000 person-years), then stabilized in short-term trends: $+0.56 \%(95 \% \mathrm{Cl}-0.83-1.97 \%$, $p=0.4)$. Incidence rates of distant disease remained stable in both short- and long-term trends (1975-2009: from 1.90 to 2.32 per 100000 person-years, APC: $+0.09 \%, p=0.5$ ).

Table 2. Long-term (1975-2009) and short-term (2000-2009) overall and stage-specific age-adjusted incidence and mortality trends

\begin{tabular}{|c|c|c|c|c|}
\hline & \multicolumn{2}{|c|}{ Long-term } & \multicolumn{2}{|c|}{ Short-term } \\
\hline & APC $(95 \% \mathrm{Cl})$ & $p$ value & APC $(95 \% \mathrm{Cl})$ & $p$ value \\
\hline \multicolumn{5}{|l|}{ Incidence } \\
\hline Overall & $+2.76(2.61,2.91)$ & $<0.001$ & $+2.85(2.06,3.64)$ & $<0.001$ \\
\hline Localized & $+4.55(4.34,4.76)$ & $<0.001$ & $+4.42(3.40,5.46)$ & $<0.001$ \\
\hline Regional & $+0.88(0.60,1.15)$ & $<0.001$ & $+0.56(-0.83,1.97)$ & 0.4 \\
\hline Distant & $0.09(-0.19,0.36)$ & 0.5 & $-1.20(-2.74,0.37)$ & 0.1 \\
\hline \multicolumn{5}{|l|}{ Mortality* } \\
\hline Overall & $+1.72(1.31,2.13)$ & $<0.001$ & $+0.77(-0.12,1.67)$ & 0.1 \\
\hline Localized & $+3.92(3.45,4.39)$ & $<0.001$ & $+3.14(1.92,4.38)$ & $<0.001$ \\
\hline Regional & $+0.99(0.33,1.65)$ & 0.004 & $-0.52(-1.43,0.40)$ & 0.2 \\
\hline Distant & $+0.30(-0.10,0.69)$ & 0.1 & $-0.83(-2.31,0.68)$ & 0.2 \\
\hline
\end{tabular}

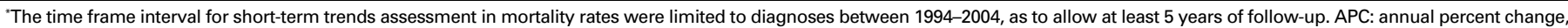
Cl: confidence interval. 
Gandaglia et al.

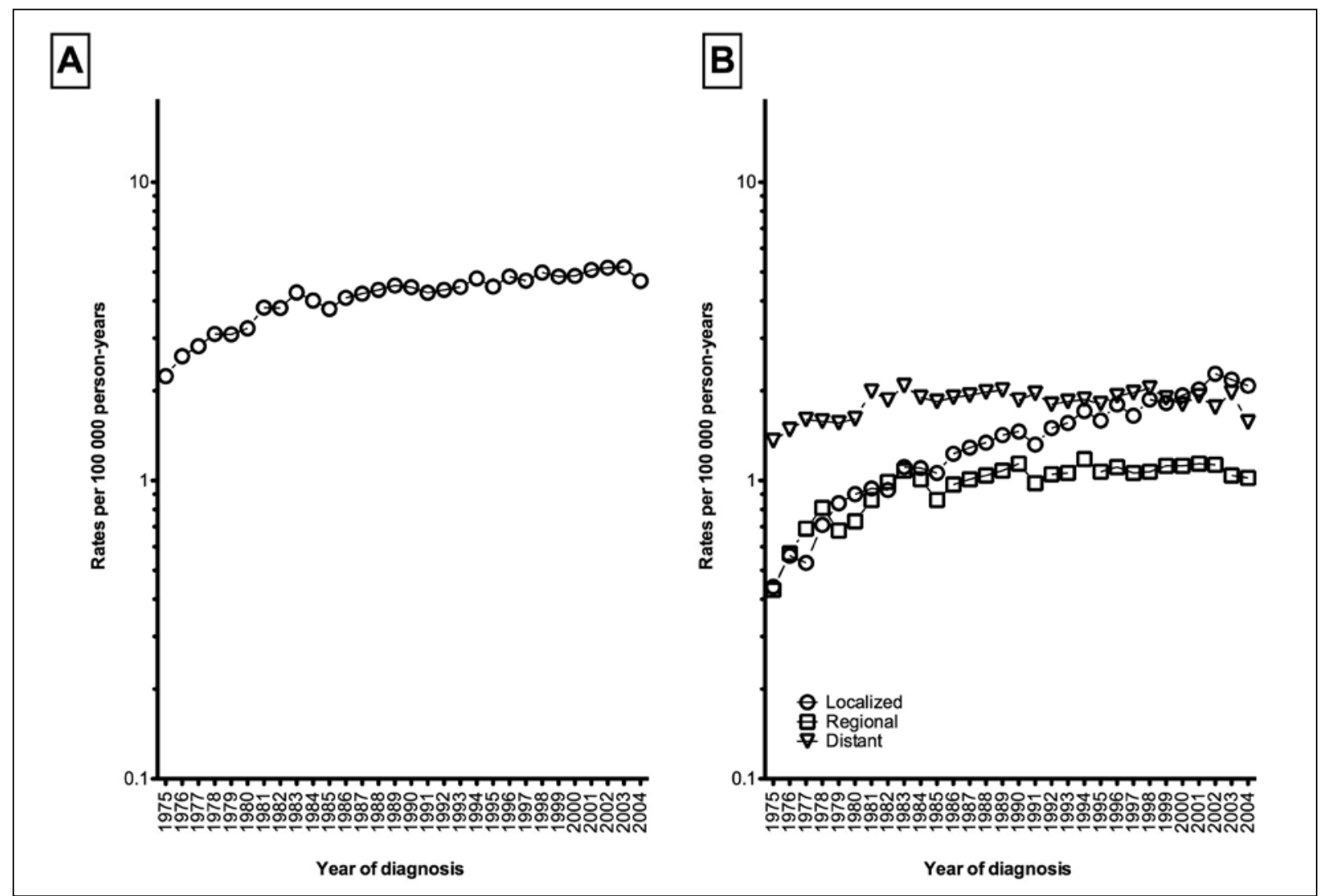

Fig. 3. Overall age-adjusted mortality rates of kidney cancer $[\mathrm{A}]$ and stratified according to disease stage $[\mathrm{B}]$, Surveillance, Epidemiology, and End Results (SEER), 1975-2004.

\section{5 -year CSS}

Overall 5-year CSS rate for kidney cancer of all stages was 60.4\% (95\% Cl 60.3-60.6\%). Between 1975 and 2005, the 5-year CSS rates significantly improved over time: from $47.5 \%(95 \% \mathrm{Cl} 46.3-48.6 \%)$ to $64.9 \%(95 \% \mathrm{Cl} 64.3-65.6 \%$, $p<0.001$, Fig. 2, part A). Stage-specific 5-year CSS rates were $87.0 \%(95 \% \mathrm{Cl} 86.8-87.2 \%)$ for localized stage, $62.9 \%(95 \% \mathrm{Cl} 62.6-63.2 \%)$ for regional stage, and $9.3 \%$ (95\% Cl 9.1-9.5\%) for distant stage. Significant improved 5 -year CSS rates were recorded for all stages over time (all $p<0.001$, Fig. 2, part B-D).

\section{Mortality}

Overall age-adjusted mortality rates increased by $+1.72 \% /$ year $(95 \% \mathrm{Cl} 1.31-2.13 \%, p<0.001)$ between 1975 and 2009 (from 2.24 to 5.00 per 100000 person-years, Fig. 3, part A, Table 2). However, mortality rates stabilized between 1994 and 2004 (APC: $+0.77 \%, 95 \% \mathrm{Cl}-0.12-1.67 \%$, $p=0.1$ ). The age-adjusted mortality rates for both localized and regional kidney cancer increased by $+3.92 \% /$ year $(95 \% \mathrm{Cl} 3.45-4.39 \%, p<0.001)$ and by $+0.99 \% /$ year $(95 \%$ Cl 0.33-1.65\%, $p=0.004$ ) between 1975 and 2009 (Fig. 3, part B), respectively. In comparison, mortality rates for distant stage remained stable over time (APC: $+0.30 \%, 95 \% \mathrm{CI}$ $-0.10-0.69 \%, p=0.1)$. Short-term trends revealed that death rates for localized stage continued to increased by $3.14 \% /$ year $(95 \% \mathrm{Cl} 1.92-4.38 \%, p<0.001)$ for those diagnosed between 1994 and 2004. In contrast, death rates for both regional (APC: $-0.52 \%, 95 \% \mathrm{Cl}-1.43-0.40 \%, p=0.2$ ) and distant stages (APC: $-0.83 \%, 95 \% \mathrm{Cl}-2.31-0.68 \%, p=0.2$ ) remained stable for those diagnosed between 1994 and 2004 (Table 2).

\section{Discussion}

In the latest seminal report published in the Journal of the National Cancer Institute by Jemal and colleagues, ${ }^{6}$ the incidence rates of 11/17 and 11/18 most common cancers for men and women either declined or stabilized between 2000 and 2009, respectively. Under such favourable improved trends for many cancers, one may ponder whether such declining incidence rates are equally applicable in the context of kidney cancer. The testing of such hypothesis becomes even more relevant given that historically, the rise in incidence of RCC has largely been attributed to the increased use of imaging techniques, which resulted in an 
increased detection of incidental tumours. ${ }^{3,4}$ However, the declining use of imaging has been recently reported. ${ }^{7}$ As a result, incidence rates of RCC should, at the minimum, have stabilized in recent years. Under such premises, we sought to examine the variations in RCC incidence and mortality in long- and short-term trends to provide a timely update of kidney cancer incidence and death rates in the United States.

First and foremost, our findings revealed that the incidence rates of kidney cancer maintain an upward trend in recent years (2000-2009), rising by nearly 3\% per year. Such a rise in incidence was largely driven by localized disease, where rates increased in a significant fashion by $4 \% /$ year, while those of regional and distant stages remained constant. It has been previously purported that the tremendous rise was the result of imaging use..$^{2-4,10}$ However, recent data indicate that the use of computed tomography appeared to flatten starting in 2007, and even reduced between 2009 and 2010, a period during which incidence rates have seen an upward trend in the current analyses. Additionally, if the increase in incidence can be solely attributed to the improved ability to detect clinically localized diseases, the proportion of patients with locally advanced and metastatic disease should theoretically decrease over time. Unfortunately, our findings indicate a lack of a concomitant decrease for both regional and distant stages in long-term trends.

The persisting rise in the incidence of localized RCC is unclear. However, such trends may indicate that improved diagnostic methods are unable to fully explain the rise. Specifically, if the implementation of novel diagnostic tools results in a precipitated increase in incidence, it should theoretically stabilize over time. Such was the case for prostate cancer, where following a nationwide diffusion of prostatespecific antigen (PSA) testing, the incidence rates of the disease rose steadily by $+16.5 \%$ /year between 1988 and 1992, ${ }^{11}$ but ultimately levelled off in recent years: $-11.2 \%$ / year between 1992 and 1995, and -2.1\%/year between 2000 and 2009 (both $p<0.05$ ). ${ }^{6}$

Other contributing etiological factors have been suggested. It has been previously established that cigarette smoking, ${ }^{12}$ body mass index, ${ }^{13}$ and hypertension ${ }^{14,15}$ have a positive correlation with the increased risk of kidney cancer. ${ }^{5,13,16,17}$ It should be stated that a clear dose-response relationship cannot be reliably determined for any of such risk factors. Nonetheless, contemporary data show that obesity is a fast-growing epidemic, affecting $\geq 33 \%$ of the population in the United States with an undisputed association with physical inactivity and hypertension. ${ }^{18}$ Moreover, roughly $20 \%$ of the population still smokes. ${ }^{19}$

Whether the rising incidence of localized kidney cancer is truly the result of concurrent etiological factors remains speculative at best. Specifically, it may be postulated that there is no real increase in incidence, but an enthused endeavour from clinicians to detect small renal masses, as a result of the non-negligible imaging use in contemporary years. Alternatively, the rising incidence could be the result of several simultaneous factors. Therefore, the exploration and testing of such hypotheses are crucial in upcoming years.

A second important finding of the current study consists of increasing mortality rates for localized disease, even in more contemporary years. Two noteworthy observations may be elaborated from such results. First, whereas the prognosis of patients with localized disease has been shown to be favourable due to earlier detection, ${ }^{20,21}$ the current results may indicate that some of these new cases are not as clinically insignificant as has been purported. Second, at the same time, a previous report suggested that surgical intervention remains the primary treatment modality for patients with localized disease. ${ }^{22}$ This unexpected disconnect between active treatment and increasing mortality rates may be suggestive of overtreatment. ${ }^{23,24}$ This is typical when novel diagnostic tools are used to detect cancers at earlier stages (e.g., prostate-specific antigen testing). While overtreatment is non-negligible in the context of small renal masses, ${ }^{25}$ the clinical dilemma persists, as some patients diagnosed with small renal masses do not live long enough to benefit from surgery, while others may harbour an aggressive disease phenotype that physicians are unable to reliably identify. ${ }^{26}$ Existing data indicate that especially among patients with competing health risks, active surveillance is a suitable approach, ${ }^{25,26}$ where a delayed intervention would not jeopardize the window of curability. ${ }^{27}$

From a clinical standpoint, our results raise significant considerations. As the incidence and mortality rates of localized RCC continues to rise, it becomes essential for physicians to better select candidates who will benefit from active treatment, and sparing those for which treatment would be unnecessary. ${ }^{26}$ Indeed, a previous review showed that most small renal masses remain radiographically static after an initial period of surveillance. ${ }^{28}$ The improved selection of surgical candidates may depend on the identification of biomarkers that can help distinguish benign and malignant disease, as well to accurately predict tumours that will metastasize.

Our findings should be evaluated within the context of population-based study limitations. As in all epidemiologic research relying on the SEER database, the lack of central pathology, consideration of loss to follow-up and lack of detailed information on TNM staging represent important potential biases that may have affected the current findings. That said, the SEER represents a large contemporary cohort that is considered highly generalizable of the United States population.

\section{Conclusion}

The persisting upward trends of localized RCC incidence and mortality suggest that the widespread use of imaging 
Gandaglia et al.

contributes to this phenomenon. Alternatively other etiological factors may be considered. An effort should be made to identify the characteristics of localized kidney tumour at higher risk of metastases and cancer-specific mortality.

Competing interests: Dr. Becker, Dr. Ravi, Dr. Gandaglia, Dr. Karakiewicz, Dr. Sun, Dr. Abdollah, Dr. Abd-El-Barr, Dr. Popa and Dr. Briganti all declare no competing financial or personal interests. Dr. Trinh has received consultant fees from Intuitive Surgical Inc. Dr. Jewett is a member of the Advisory Board for Pfizer. He has also received grants from Novartis, GSK and Pfizer. Lastly, he has participated in clinical trials with Novartis, GSK and Pfizer.

This paper has been peer-reviewed.

\section{References}

1. Siegel R, Naishadham D, Jemal A. Cancer statistics, 2012. CA Cancer J Clin 2012;62:10-29. http:// dx.doi.org/10.3322/caac.20138

2. Sun $M$, Thuret $R$, Abdollah $F$, et al. Age-adjusted incidence, mortality, and survival rates of stage-specific renal cell carcinoma in North America: A trend analysis. Eur Urol 2011;59:135-41.

3. Chow WH, Devesa SS, Warren JL, et al. Rising incidence of renal cell cancer in the United States. JAMA 1999;281:1628-31. http://dx.doi.org/10.1001/jama.281.17.1628

4. Hollingsworth JM, Miller DC, Daignault $S$, et al. Rising incidence of small renal masses: A need to reassess treatment effect. J Natl Cancer Inst 2006;98:1331-4. http://dx.doi.org/10.1093/inci/dij362

5. Chow W-H, Dong LM, Devesa SS. Epidemiology and risk factors for kidney cancer. Nat Rev Urol 2010;7:245-57. htrp://dx.doi.org/10.1038/nrurol.2010.46

6. Jemal A, Simard EP, Dorell C, et al. Annual Report to the Nation on the Status of Cancer, 1975-2009, featuring the burden and trends in human papillomavirus (HPV)-associated cancers and HPV vaccination coverage levels. J Natl Cancer Inst 2013;105:175-201. htrp://dx.doi.org/10.1093/inci/dis491

7. Smith-Bindman R, Miglioretti DL, Johnson E, et al. Use of diagnostic imaging studies and associated radiation exposure for patients enrolled in large integrated health care systems, 1996-2010. JAMA 2012;307:2400-9. http://dx.doi.org/10.1001/jama.2012.5960

8. National Cancer Institute. Surveillance Epidemiology and End Results (SEER) Program. http://seer.cancer. gov/popdata/methods.html. Accessed July 24, 2014.

9. Kim HJ, Fay MP, Fever EJ, et al. Permutation tests for joinpoint regression with applications to cancer rates. Statist Med 2000;19:335-51. http://dx.doi.org/10.1002/(SICI) 1097 . 0258(20000215) 19:3<335::AID-SIM336>3.0.C0;2-2

10. Sun $M$, Abdollah $F$, Bianchi $M$, et al. A stage-for-stage and grade-for-grade analysis of cancer-specific mortality rates in renal cell carcinoma according to age: A competing-risks regression analysis. Eur Urol 2011;60:1152-9. http://dx.doi.org/10.1016/i.eururo.2011.07.064

11. Jemal A, Thun MJ, Ries LAG, et al. Annual report to the nation on the status of cancer, 1975-2005, featuring trends in lung cancer, tobacco use, and tobacco control. J Natt Cancer Inst 2008;100:1672-94. http://dx.doi.org/10.1093/inci/din389
12. Hunt JD, van der Hel OL, McMillan GP, et al. Renal cell carcinoma in relation to cigarette smoking: Meta-analysis of 24 studies. Int I Cancer 2005;114:101-8. http://dx.doi.org/10.1002/iic.20618

13. Renehan AG, Tyson $M$, Egger $M$, et al. Body-mass index and incidence of cancer: A systematic review and meta-analysis of prospective observational studies. Lancet 2008;371:569-78. http://dx.doi. org/10.1016/S0140-6736(08)60269-X

14. Chow WH, Gridley G, Fraumeni JF, et al. Obesity, hypertension, and the risk of kidney cancer in men. $N$ Engl J Med 2000;343:1305-11. hitr://dx.doi.org/10.1056/NEJM200011023431804

15. Weikert $S$, Boeing $H$, Pischon $T$, et al. Blood pressure and risk of renal cell carcinoma in the European prospective investigation into cancer and nutrition. Am J Epidemiol 2008;167:438-46. http://dx.doi. org/10.1093/aje/kwm321

16. Liungberg B, Campbell SC, Choi HY, et al. The epidemiology of renal cell carcinoma. Eur Urol 201 1;60:61521. http://dx.doi.org/10.1016/i.eururo.2011.06.049

17. Daniel CR, Park Y, Chow W-H, et al. Intake of fiber and fiber-rich plant foods is associated with a lower risk of renal cell carcinoma in a large US cohort. Am J Clin Nutr 2013;97:1036-43. http://dx.doi. org/10.3945/ajcn.112.045351

18. Flegal KM, Carroll MD, Kit BK, et al. Prevalence of obesity and trends in the distribution of body mass index among US adults, 1999-2010. JAMA 2012;307:491-7. http://dx.doi.org/10.1001/jama.2012.39

19. Centers for Disease Control and Prevention (CDC). Current cigarette smoking among adults - United States, 2011. MMWR Morb Mortal Wkly Rep 2012;61):889-94.

20. Liungberg B, Cowan NC, Hanbury DC, et al. EAU guidelines on renal cell carcinoma: The 2010 update. Eur Urol 2010;58:398-406. http://dx.doi.org/10.1016/i.eururo.2010.06.032

21. Nguyen MM, Gill IS, Ellison LM. The evolving presentation of renal carcinoma in the United States: trends from the Surveillance, Epidemiology, and End Results program. J Urol 2006;176 (6 Pt 1):2397-400, discussion 2400.

22. Sun $M$, Abdollah $F$, Bianchi $M$, et al. Treatment management of small renal masses in the 21 st century: A paradigm shift. Ann Surg Oncol 2012;19:2380-7. http://dx.doi.org/10.1245/s10434-012-2247-0

23. Hollingsworth $J M$, Miller DC, Daignault $S$, et al. Five-year survival after surgical treatment for kidney cancer: A population-based competing risk analysis. Cancer 2007;109:1763-8. http://dx.doi.org/10.1002/ cncr.22600

24. Welch HG, Black WC. Overdiagnosis in cancer. J Natl Cancer Inst 2010;102:605-13. http://dx.doi. org/10.1093/inci/diq099

25. Kutikov A, Egleston BL, Wong Y-N, et al. Evaluating overall survival and competing risks of death in patients with localized renal cell carcinoma using a comprehensive nomogram. J Clin Oncol 2010;28:311-7. http://dx.doi.org/10.1200/JC0.2009.22.4816

26. Sun M, Becker A, Tian Z, et al. Management of localized kidney cancer: Calculating cancer-specific mortality and competing risks of death for surgery and nonsurgical management. Eur Urol 2014;65:235-41. http://dx.doi.org/10.1016/i.eururo.2013.03.034. Epub 2013 Mar 27.

27. Crispen PL, Viterbo R, Fox EB, et al. Delayed intervention of sporadic renal masses undergoing active surveillance. Cancer 2008;112:1051-7. http://dx.doi.org/10.1002/cncr.23268

28. Smaldone MC, Kutikov A, Egleston BL, et al. Small renal masses progressing to metastases under active surveillance. Cancer 2011;118:997-1006. http://dx.doi.org/10.1002/cncr.26369

Correspondence: Dr. Maxine Sun, Cancer Prognostics and Health Outcomes Unit University of Montreal Health Centre, Montreal, QC; fax: 514-227-5103; mcw.sun@umontreal.ca 